\title{
Role of Sandwich Cu Layer in and Effect of Self-Bias on Nanomechanical Properties of Copper/Diamond-Like Carbon Bilayer Films
}

\author{
Neeraj Dwivedi, ${ }^{1,2}$ Sushil Kumar, ${ }^{1}$ Hitendra K. Malik, ${ }^{2}$ C. M. S. Rauthan, ${ }^{1}$ and O. S. Panwar ${ }^{1}$ \\ ${ }^{1}$ Physics of Energy Harvesting Division, National Physical Laboratory (CSIR), Dr. K.S. Krishnan Road, New Delhi 110012, India \\ ${ }^{2}$ Department of Physics, Indian Institute of Technology Delhi, New Delhi 110016, India \\ Correspondence should be addressed to Sushil Kumar, skumar@nplindia.org
}

Received 10 March 2011; Accepted 9 April 2011

Academic Editors: C. A. Charitidis, S. Dub, B. R. Kimball, and B. Pignataro

Copyright () 2011 Neeraj Dwivedi et al. This is an open access article distributed under the Creative Commons Attribution License, which permits unrestricted use, distribution, and reproduction in any medium, provided the original work is properly cited.

\begin{abstract}
The role of sandwich $\mathrm{Cu}$ layer in and effect of self-bias on structural and nanomechanical properties of Cu/DLC bilayer films have been explored. Cu/DLC bilayer films were grown, under varied self-bias from -125 to $-225 \mathrm{~V}$, using hybrid system involving radiofrequency- (RF-) plasma-enhanced chemical vapor deposition and RF-sputtering units. Surface topography and mean roughness was studied by atomic force microscope and then correlated with mechanical properties. The addition of sandwich Cu layer in DLC reduces its residual stress and does not affect bilayer film hardness and elastic modulus. Load versus displacement was also employed to estimate various other mechanical parameters, which further correlated with self-bias and structural properties. These $\mathrm{Cu} / \mathrm{DLC}$ bilayer films seem to be a potential candidate for various industrial applications such as hard and protective coating on cutting tools, solar cells, and wear resistance coating on magnetic storage media.
\end{abstract}

\section{Introduction}

Due to difficulty in preparation of diamond in the laboratories, the diamond-like carbon (DLC) thin films, which exhibit properties similar to that of diamond such as high hardness, high transmission, and higher thermal conductivity, have attracted considerable attention of researchers across the world [1-7]. Recently, DLC film has also been undertaken to explore its distinguishable electronic properties, which results in its applications in the development of solar cells, field emission devices, and microelectromechanical systems (MEMS) [8-14]. However, besides versatile mechanical and electronic properties the DLC films have a big drawback of its poor adhesion with substrate due to existence of excessive residual stress [15]. High residual stress limits the growth of comparatively thick DLC films, which restricted its potential industrial applications. The incorporation of nitrogen in DLC films reduces its residual stress but with some sacrifice of hardness $[2,16]$. Thus, there is keen interest to improve the adhesion of DLC films without affecting its other mechanical properties such as hardness. Metal incorporation improves the adhesion of DLC films with substrate without affecting its other mechanical properties such as hardness $[6,17]$. However, the processing of metal-incorporated DLC films was found to be quite complex due to target poisoning problem [18]. The deposition of metal/DLC bilayer structure can be an appropriate approach to improve adhesion as well as other mechanical properties of DLC films. Since Ti and Si both form carbide therefore, some reports pertained to designing of Ti/DLC and Si/DLC bilayer and multilayer structures for improving their mechanical properties were found in the literature $[14,19]$. In contrast, negligible efforts related to designing of $\mathrm{Cu} / \mathrm{DLC}$ bilayer films for improving their mechanical properties were found in the literature.

Therefore, in the present work we explored the role of sandwich $\mathrm{Cu}$ layer and effect of self-bias on nanomechanical and structural properties of Cu/DLC bilayer films, deposited under varied self bias from -125 to $-225 \mathrm{~V}$ using hybrid system combining radio frequency-plasma-enhanced 


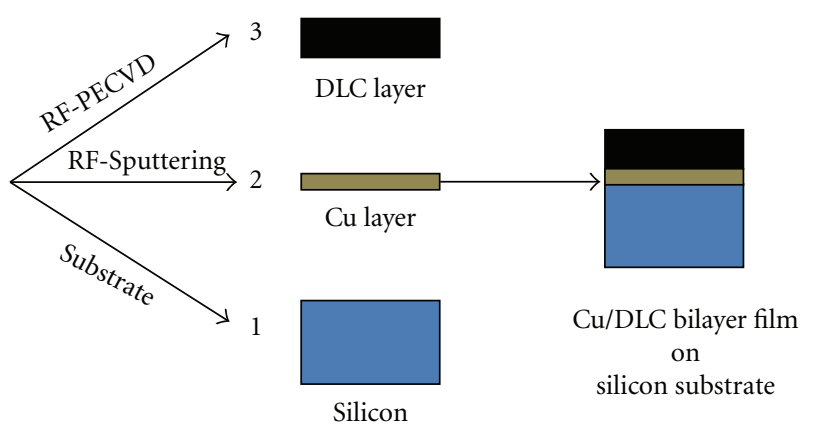

FIGURE 1: Schematic representation of designing of Cu/DLC bilayer films.

chemical vapor deposition (RF-PECVD) and RF-sputtering units. Recently, we have also prepared nanostructured $\mathrm{Cu} / \mathrm{a}-$ $\mathrm{C}: \mathrm{H}$ multilayer structure [20] using the same hybrid system. Various structural and mechanical properties such as surface morphology, mean roughness $\left(R_{a}\right)$, residual stress $(\sigma)$, hardness $(H)$, elastic modulus $(E)$, and various other mechanical parameters such as plastic resistance parameter $(H / E)$, elastic recovery (ER), ratio of residual displacement after load removal with displacement at maximum load $\left(h_{\text {res }} / h_{\text {max }}\right)$, plastic deformation energy $\left(U_{r}\right)$, contact stiffness $\left(S_{\max }\right)$, hardness per unit stress $(H / \sigma)$, and plastic resistance parameter per unit stress $[(H / E) / \sigma]$ were estimated in $\mathrm{Cu} / \mathrm{DLC}$ bilayer films.

\section{Experimental Details}

$\mathrm{Cu} / \mathrm{DLC}$ bilayer films were grown using hybrid system involving radio-frequency plasma-enhanced chemical vapor deposition (RF-PECVD) and RF-sputtering units, on Silicon (Si) $\langle 100\rangle$ substrate, at a base pressure of $1 \times 10^{-5}$ Torr. Prior to deposition, Si substrates were cleaned first ultrasonically with trichloroethylene followed by their treatment with isopropyl alcohol and finally by deionized water. The schematic representation of designing of $\mathrm{Cu} / \mathrm{DLC}$ bilayer films is shown in Figure 1. From the figure, it is clear that three steps are used to deposit Cu/DLC bilayer films. Firstly, well-cleaned Si substrate was placed in the processing chamber followed by deposition of sandwich $\mathrm{Cu}$ layer using RF-sputtering technique. Further, DLC layer was grown on successive $\mathrm{Cu}$ layer using RF-PECVD technique to form Cu/DLC bilayer structure. The sandwich $\mathrm{Cu}$ layer was grown at constant self bias and constant working Ar gas pressure of $-400 \mathrm{~V}$ and 20 mTorr, respectively. Thus, the contribution of $\mathrm{Cu}$ layer was kept the same in all the films. However, DLC layer was grown on successive $\mathrm{Cu}$ layer under varied self bias from -125 to $-225 \mathrm{~V}$ with maintaining constant working pressure of 1 mTorr, which was achieved by feeding $\mathrm{C}_{2} \mathrm{H}_{2}$ gas into the process chamber. Pure DLC film without sandwich layer $(\mathrm{Cu}$ layer) was also grown at $-125 \mathrm{~V}$ to visualize the role of sandwich $\mathrm{Cu}$ layer on $\sigma$ and various other nanomechanical properties of $\mathrm{Cu} / \mathrm{DLC}$ bilayer films.

Atomic force microscopic study was carried out using Nanoscope Veeco $V$ instrument. The residual stress in these $\mathrm{Cu} / \mathrm{DLC}$ bilayer films deposited on silicon wafer were

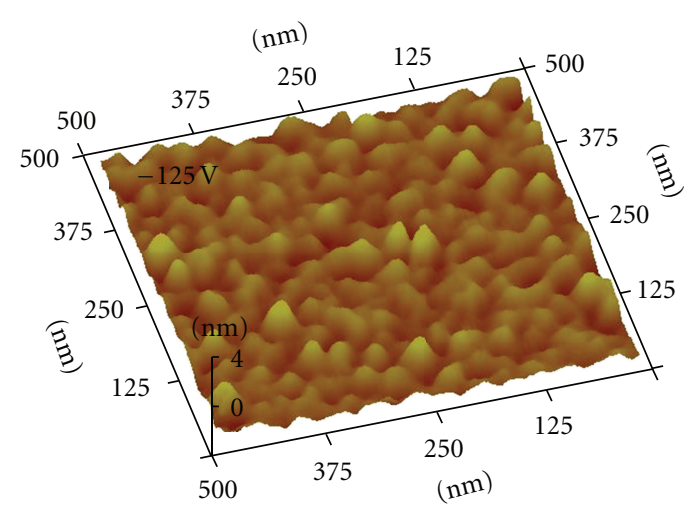

(a)

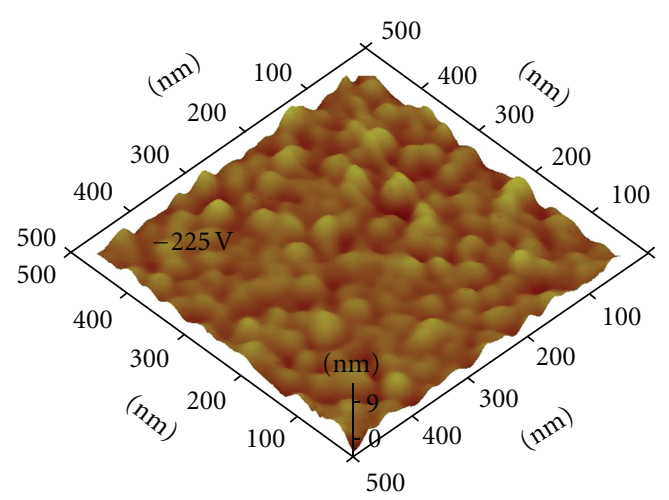

(b)

Figure 2: AFM pictures of Cu/DLC bilayer films deposited at self bias $-125 \mathrm{~V}$ and $-225 \mathrm{~V}$.

determined from the change in the radius of curvature of the wafer, before and after deposition, using 500TC temperature controlled film stress measurement system $(\mathrm{M} / \mathrm{s}$ FSM Frontier Semiconductor, USA). Stoney formula was used to evaluate residual stress and is given by the following equation: $[2,20]$

$$
\sigma=\frac{E_{s} d_{\mathrm{s}}^{2}}{6\left(1-v_{s}\right) d_{f}}\left(\frac{1}{R_{f}}-\frac{1}{R_{0}}\right),
$$

where $E_{s}, v_{s}$, and $d_{s}$ are Young's modulus, Poisson ratio, and thickness of the substrate, respectively and $R_{0}$ and $R_{f}$ are the radii of substrate curvature before and after film deposition. IBIS nanoindentation (Fisher-Cripps laboratories Pvt. Limited, Australia) having triangular pyramid diamond Berkovich indenter with normal angle of $65.3^{\circ}$ between the tip axis and the faces of triangular pyramid and the curvature of $150-200 \mathrm{~nm}$ at the tip was used to study the mechanical properties of Cu/DLC bilayer films. The maximum indentation load of $5 \mathrm{mN}$ was fixed in all the measurements. The thicknesses of these $\mathrm{Cu} / \mathrm{DLC}$ bilayer films were measured by Taylor-Hobson Talystep instrument and found to be $337,348,357$, and $376 \mathrm{~nm}$ at self bias of $-125,-150,-175$, and $-225 \mathrm{~V}$, respectively. The thickness of single DLC layer grown at $-125 \mathrm{~V}$ was found to be $310 \mathrm{~nm}$. The thickness of sandwich Cu layer was found to be $\sim 27 \mathrm{~nm}$. 


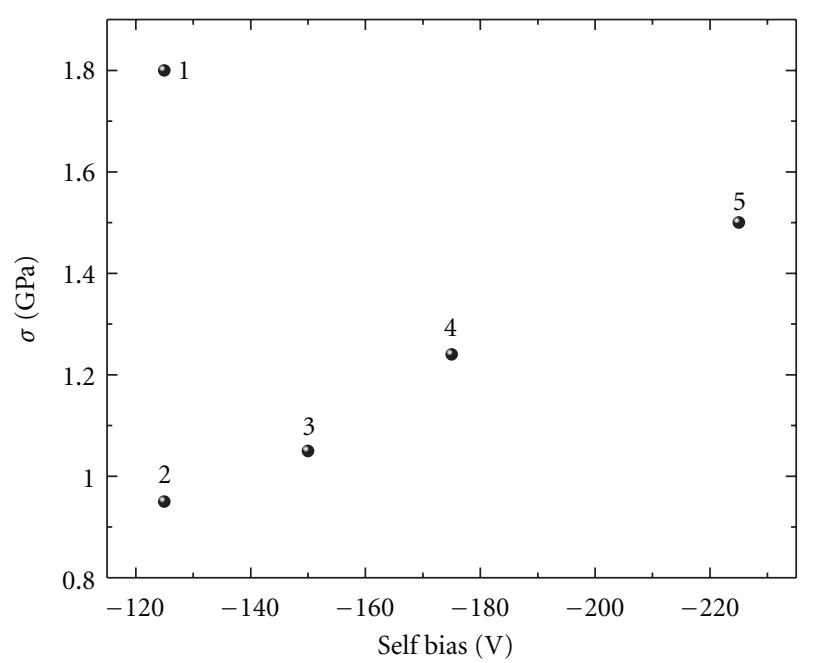
(1) DLC $(-125 \mathrm{~V})$
(4) $\mathrm{Cu} / \mathrm{DLC}(-175 \mathrm{~V})$
(2) $\mathrm{Cu} / \mathrm{DLC}(-125 \mathrm{~V})$
(5) $\mathrm{Cu} / \mathrm{DLC}(-225 \mathrm{~V})$
(3) $\mathrm{Cu} / \mathrm{DLC}(-150 \mathrm{~V})$

Figure 3: Variation of residual stress versus self bias for DLC and $\mathrm{Cu} / \mathrm{DLC}$ bilayer films.

\section{Results and Discussion}

3.1. Atomic Force Microscopy (AFM) Analysis. Surface topography and mean roughness $\left(R_{a}\right)$ of $\mathrm{Cu} / \mathrm{DLC}$ bilayer films have been studied using atomic force microscopy (AFM) technique. AFM pictures of $\mathrm{Cu} / \mathrm{DLC}$ bilayer films deposited at self bias -125 and $-225 \mathrm{~V}$ are shown in Figure 2. Observed AFM pictures clearly reveal the nanostructured morphology in which particles are uniformly distributed over entire surface. Recently, we observed nanostructured morphology by employing $\mathrm{Cu} / \mathrm{a}-\mathrm{C}: \mathrm{H}$ multilayer structure [20]. The size of particles in $\mathrm{Cu} / \mathrm{DLC}$ bilayer films was found to increase with increasing self bias. The particle size for $\mathrm{Cu} / \mathrm{DLC}$ bilayer film deposited at $-125 \mathrm{~V}$ was found to be $\sim 52 \mathrm{~nm}$ which increases to $\sim 58 \mathrm{~nm}$ for the film deposited at $-225 \mathrm{~V}$. The reason for nominal increase in particle size may be the local heating generated due to increase of self bias. Further, observed $R_{a}$ values followed similar trend and found to increase with increasing self bias. The value of $R_{a}$ for Cu/DLC bilayer film deposited at $-125 \mathrm{~V}$ was found to be $0.31 \mathrm{~nm}$ which increases to $0.69 \mathrm{~nm}$ for the film deposited at $-225 \mathrm{~V}$. It is interesting to note that $R_{a}$ in these films was found to be very low, which reveal the surfaces are very smooth and flat. However, observed small increase in $R_{a}$ with increase of self bias may be due to increase of energy of bombardment carbon atom, which causes generation of local heating at $\mathrm{Cu} / \mathrm{C}$ interface that results in interfacial mismatching. The results of $R_{a}$ have been correlated with residual stress as well as other nanomechanical properties.

3.2. Stress $(\sigma)$. Reduction of residual stress $(\sigma)$ in DLC films was found to be an important aspect of research till date. High level of $\sigma$ in DLC films restricts its potential industrial

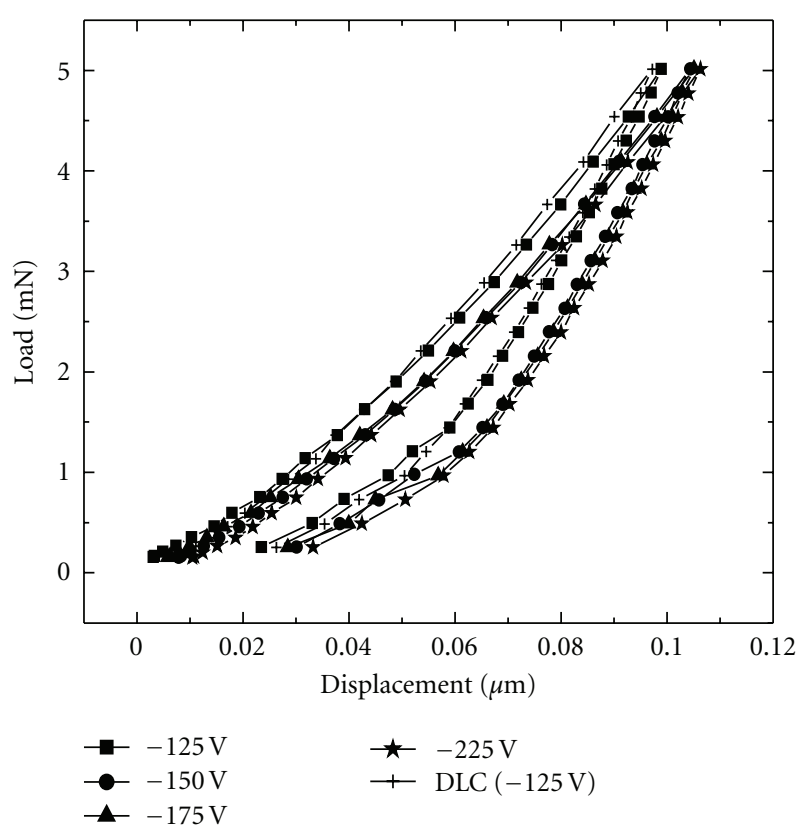

Figure 4: Load versus displacement curves of DLC and Cu/DLC bilayer films grown at self biases of $-125,-150,-175$, and $-225 \mathrm{~V}$.

applications. Thus, minimization of $\sigma$ in DLC films is very important to enhance its practical applications. Variation of $\sigma$ versus self bias for Cu/DLC bilayer films is depicted in Figure 3. Besides Cu/DLC bilayer films, the $\sigma$ of DLC film deposited at $-125 \mathrm{~V}$ was also calculated to visualize the role of sandwich $\mathrm{Cu}$ layer. The $\sigma$ was found to be compressive in nature. Drastic decrease in value of $\sigma$ was observed when sandwich $\mathrm{Cu}$ layer introduce between substrate Si and DLC layer. The value of $\sigma$ at $-125 \mathrm{~V}$ in DLC and $\mathrm{Cu} / \mathrm{DLC}$ bilayer films were found to be 1.8 and $0.95 \mathrm{GPa}$, respectively. In DLC films, it was found that ions/atoms bombardment induces some local heating at $\mathrm{Si} / \mathrm{C}$ interface that causes interdiffusion of $\mathrm{C}$ atoms into $\mathrm{Si}$ and results in formation of ultrathin $\mathrm{SiC}$ layer at Si/C interface. Thus, interfacial stress is caused by mismatch between $\mathrm{C}$ and $\mathrm{Si}$ atoms [21]. Another possibility of $\sigma$ in DLC film was found to be the existence of disorder (deviation in bond length and bond angle) in its structure. Kumar et al. have already studied the stress in terms of disorder [22]. Nonetheless, high level of $\sigma$ was prevented by placing sandwich $\mathrm{Cu}$ layer in between substrate $\mathrm{Si}$ and DLC layer. This sandwich $\mathrm{Cu}$ layer prevents interdiffusion of $\mathrm{C}$ atoms into Si. Further, addition of sandwich $\mathrm{Cu}$ layer may also result in incoherent stress relaxation as well as percolation structural transition from a-C : H-rich structure to carbide-rich structure [23]. However, $\sigma$ in $\mathrm{Cu} / \mathrm{DLC}$ bilayer films was found to continuously increase from 0.95 to $1.5 \mathrm{GPa}$ with increase in self bias from -125 to $-225 \mathrm{~V}$, respectively. It is expected that with the increase of self bias the ions/atoms bombardment becomes more energetic and causes some mismatch at $\mathrm{Cu} / \mathrm{C}$ interface. Further, observed increase in $\sigma$ with increase of self bias may also be due to increase of $R_{a}$ because increase in $R_{a}$ corresponds to more changes in the radius of curvature of surface. 


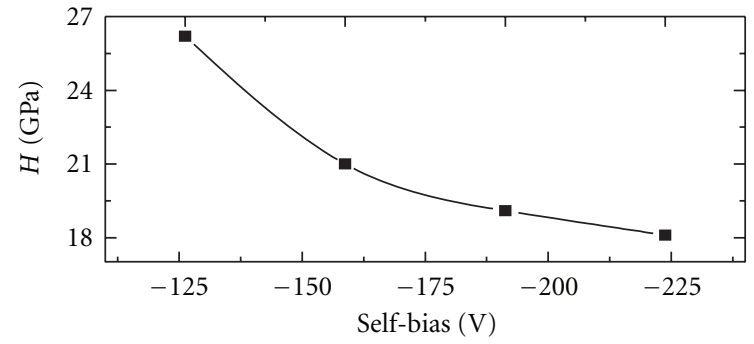

(a)

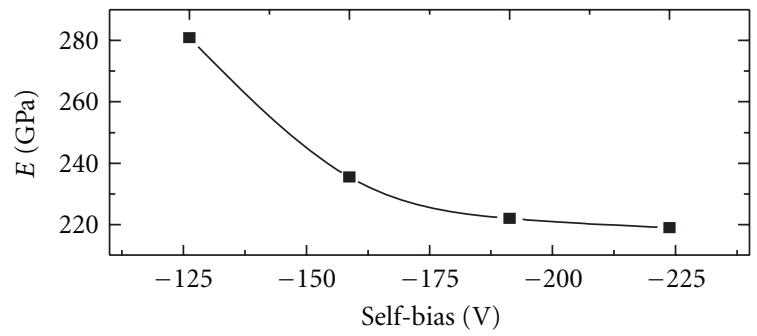

(b)

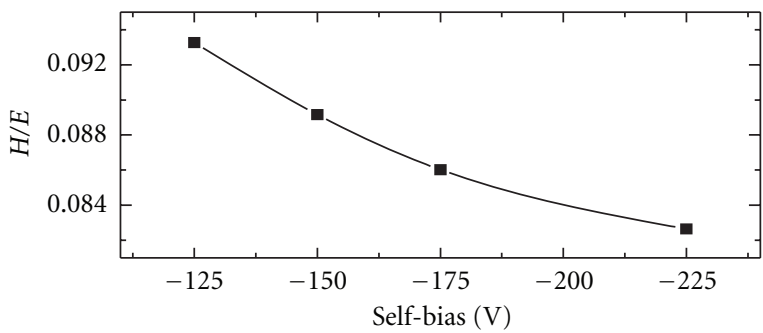

(c)

Figure 5: Variation of self bias versus (a) $H$, (b) $E$, and (c) $H / E$ for various $\mathrm{Cu} / \mathrm{DLC}$ bilayer films.

3.3. Nanoindentation Measurements. Due to its sound resolution characteristic, nanoindentation was found as an excellent technique to study the nanomechanical properties of thin films. The load versus displacements curves of DLC and Cu/DLC bilayer films grown at different self bias $-125,-150,-175$, and $-225 \mathrm{~V}$ is shown in Figure 4 . It is to be noted that if indenter penetrate one third of total film thickness, then substrate also influence mechanical properties, and the result shows composite substrate/film effect. Due care was taken to avoid substrate effect but unable to do this completely due to lower film thickness. However, for this the $H$ of Si wafer was measured before the depositions and then $H$ of substrate/film was estimated by composite hardness model [24]. The variation of $H$ and $E$ versus self bias for $\mathrm{Cu} / \mathrm{DLC}$ bilayer films is depicted in Figures 5(a) and 5(b), respectively. $H$ and $E$ of pure DLC films were also estimated, and their values were found to be 25.1 and 257.2 GPa, respectively. It is interesting to note that with addition of sandwich $\mathrm{Cu}$ layer nominal increase in values of $H$ and $E$ was observed in Cu/DLC bilayer films. It is evident from the figure that $H$ of $\mathrm{Cu} / \mathrm{DLC}$ bilayer films were found to continuously decrease with increasing self bias. The values of $H$ at $-125,-150,-175$, and $-225 \mathrm{~V}$ were found to be $26.2,21,19.1$, and $18.1 \mathrm{GPa}$, respectively. Observed $E$ values

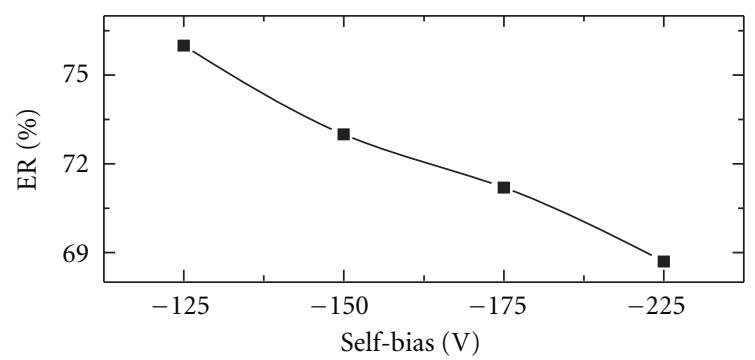

(a)

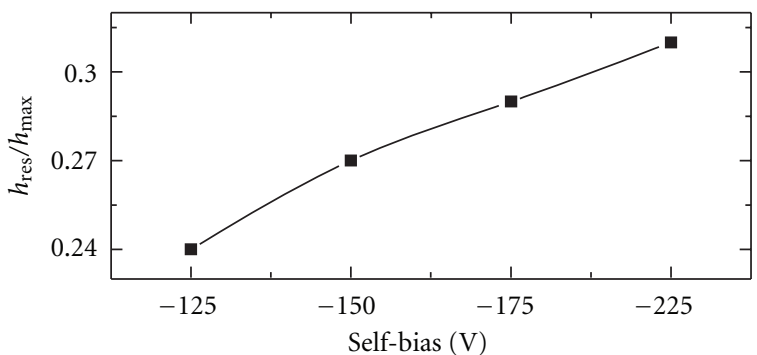

(b)

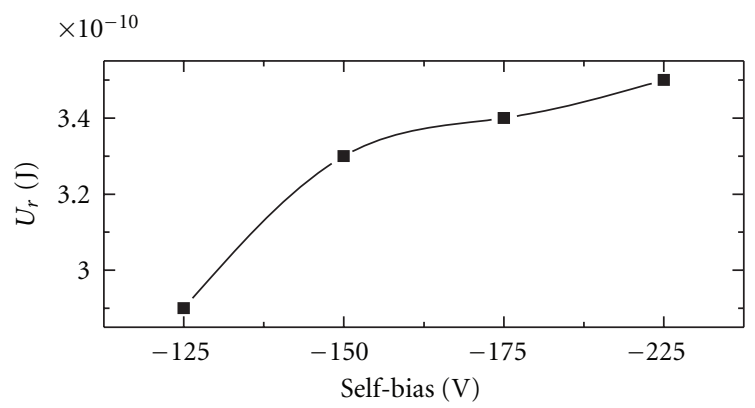

(c)

Figure 6: Variation of self bias versus (a) ER, (b) $h_{\text {res }} / h_{\text {max }}$, and (c) $U_{r}$ for various $\mathrm{Cu} / \mathrm{DLC}$ bilayer films.

in $\mathrm{Cu} / \mathrm{DLC}$ bilayer films followed similar trend and found to decrease from 280.9 to $219 \mathrm{GPa}$ with increase in self bias from -125 to $-225 \mathrm{~V}$, respectively. The $H$ of DLC and Cu/DLC bilayer films strongly depends on various hybridization states and can be tuned by controlling its bonding configuration. DLC film comprises of strong $\mathrm{sp}^{3} \mathrm{C}-\mathrm{C}$ and soft $\mathrm{sp}^{2} \mathrm{C}-\mathrm{C}$ bondings. The enhancement of $\mathrm{sp}^{3} \mathrm{C}-\mathrm{C}$ bondings results in increase of $H$ and vice versa. The ion energy which is a function of self bias and varies proportional to RF power and self bias controls the various bondings in DLC films. Erdemir and Donnet [25] in their review described that lower, intermediate, and higher ion energy is required to obtain polymer-like carbon (due to insufficient dissociation), diamond-like carbon (due to sufficient dissociation and highly dense network), and graphite-like carbon (due to increase in $\mathrm{sp}^{2}$ induced disorder) films. Fallon et al. [26] reported maximum $\mathrm{sp}^{3} \mathrm{C}-\mathrm{C}$ bonding in filtered cathodic vacuum arc grown tetrahedral amorphous carbon films at $\sim 100 \mathrm{eV}$ beyond which they observed the initiation of graphite-like bonding. Singh et al. [27] obtained maximum $\mathrm{sp}^{3}$ bonding with maximum $H$ at $-150 \mathrm{~V}$. Recently, we also 


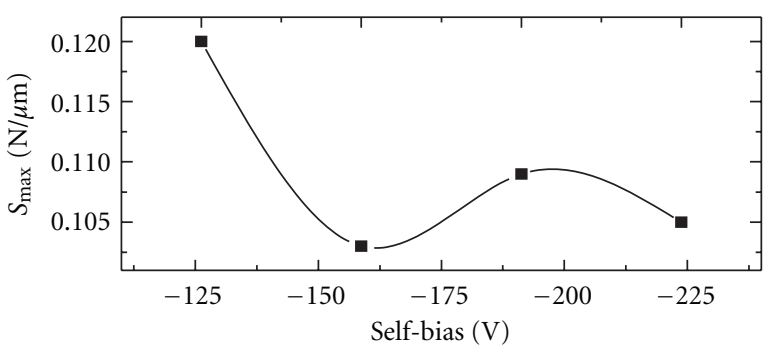

(a)

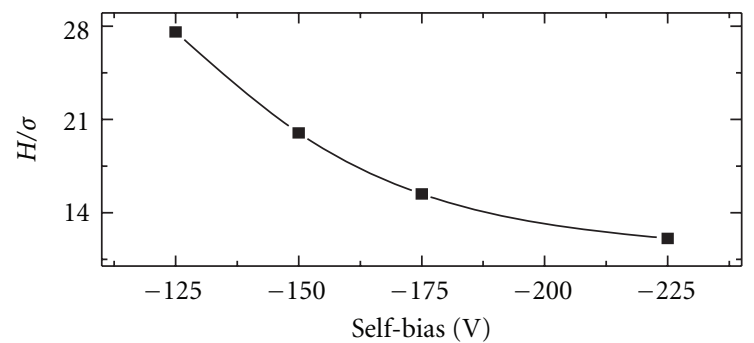

(b)

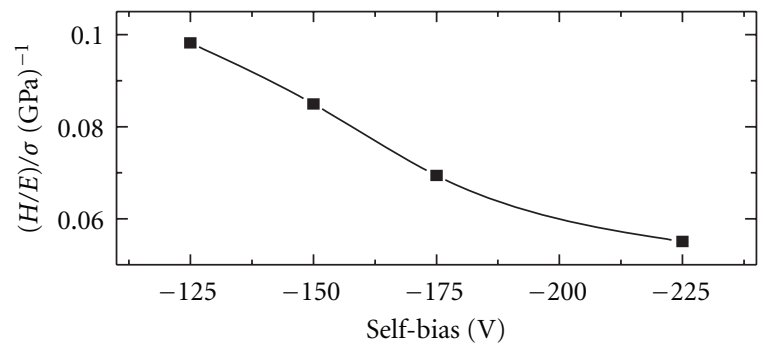

(c)

Figure 7: Variation of self bias versus (a) $S_{\max }$, (b) $H / \sigma$ and (d) $(H / E) / \sigma$ for various $\mathrm{Cu} / \mathrm{DLC}$ bilayer films.

observed diamond-like coating at self bias between -100 and $-130 \mathrm{~V}[2,10]$. Thus, in the present study observed higher $H$ in $\mathrm{Cu} / \mathrm{DLC}$ bilayer film at $-125 \mathrm{~V}$ was due to its diamondlike character. However, reduction in both $H$ and $E$ beyond self bias $-125 \mathrm{~V}$ was due to initiation of soft graphite-like $\mathrm{sp}^{2} \mathrm{C}-\mathrm{C}$ bondings. The surface properties also influence the nanomechanical properties significantly. Since the increase in self bias enhances the $R_{a}$ of Cu/DLC bilayer films, therefore observed decrease in $H$ with increase of self bias may also be due to increase in its $R_{a}$ values. As nanostructured morphology was observed in Cu/DLC bilayer films, then $H$ can also be explained by Hall-Petch theory that describes $H$ varies inversely with size of particles [28]. Therefore, observed decrease in $H$ with increase of self bias was due to increase in particle size. Plastic resistance parameter $(H / E)$ was found to be an important parameter which clearly differentiates elastic and elastic-plastic behavior of thin films $[2,10]$. Also for protective and high wear resistance coating, the parameter $H / E$ must be very highThis parameter enable even less hard films having high $H / E$ that may be useful for same application. The variation of $H / E$ against self bias for $\mathrm{Cu} / \mathrm{DLC}$ bilayer films is shown in Figure 5(c). Maximum value of $H / E$ was obtained at $-125 \mathrm{~V}$, which further decreases with increasing self bias. Higher $H / E(0.093)$ at $-125 \mathrm{~V}$ shows its better wear resistance property. However, the observed decrease in $H / E$ with increase in self bias reveals more fraction of work consumed in plastic deformation, and large plastic strain is expected when contacting a material. Load versus displacement curves was further employed to estimate \%ER. The value of \%ER was calculated using the relation $[2,3]$ given by the following equation:

$$
\% \mathrm{ER}=\frac{\left(h_{\max }-h_{\mathrm{res}}\right)}{h_{\max }} \times 100,
$$

where $h_{\max }$ and $h_{\text {res }}$ are the displacement at the maximum load and residual displacement after load removal, respectively. The variation of \%ER versus self bias is plotted in Figure 6(a). The ER of Cu/DLC bilayer films was found to continuously decrease with increasing self bias and found to be $76,73,71.2$, and $68.7 \%$ at $-125,-150,-175$, and $-225 \mathrm{~V}$, respectively. Observed decrease in ER with increase of self bias confirmed the initiation of soft graphite-like bonding which induces some plasticity in the structure. Decrease of ER with increase of self bias may also be due to the increase of $R_{a}$ as well as increase of particle size. It should be noted that $h_{\text {res }} / h_{\max }$ ratio also gives information similar to that of \%ER with different domains of validity. Typically, the domain of validity of $h_{\mathrm{res}} / h_{\max }$ ratio varies between 0 and 1 . The lower limit corresponds to fully elastic, and the upper limit corresponds to elastic-plastic behavior, respectively. The variation of $h_{\text {res }} / h_{\max }$ versus self bias is shown in Figure 6(b). The values of $h_{\text {res }} / h_{\max }$ were found to increase from 0.24 to 0.31 with increase in self bias from -125 to $-225 \mathrm{~V}$. Observed lower values of $h_{\text {res }} / h_{\max }$ reveal its highly elastic behaviour. Plastic deformation energy $\left(U_{r}\right)$ was also calculated to explore elastic-plastic properties further. Generally $U_{r}$ of the film is estimated by area surrounded by the loading-unloading curve in the load-displacement profile. $U_{r}$ possesses a relation with $H[2,10]$, which is given by the following equation:

$$
U_{r}=\left[\frac{1}{3} \sqrt{\frac{1}{\omega_{0} \tan ^{2} \Psi}}\right] \frac{1}{\sqrt{H}} P^{3 / 2},
$$

where $\omega_{0}$ is the geometry constant and attains the value of 1.3 for pyramid indenter, $P$ is the load, and $\Psi$ is the half angle of Berkovich indenter and have the value $65.3^{\circ}$. Figure 6(c) shows the variation of $U_{r}$ versus self bias for different $\mathrm{Cu} / \mathrm{DLC}$ bilayer films. The values of $U_{r}$ were found to be in the range from $2.9 \times 10^{-10}$ to $3.5 \times 10^{-10} \mathrm{~J}$ with change in self bias from -125 to $-225 \mathrm{~V}$. Observed very low values $U_{r}$ in $\mathrm{Cu} / \mathrm{DLC}$ bilayer films again confirmed these films were found to be more elastic and less plastic in nature. It is evident that values of $U_{r}$ slightly increase with increasing self bias due to initiation of soft graphite-like bonding, which correspond to some plasticity and results in decrease of $H$ and recovery ability, that is, decrease of ER. Load versus displacement curves were also employed to estimate unloading stiffness at maximum load $\left(S_{\max }\right)$. The $S_{\max }$ was calculated by taking the slope of unloading curve at maximum load. The variation of $S_{\max }$ against self bias is depicted in Figure 7(a). Observed comparatively higher value of $S_{\max }$ at $-125 \mathrm{~V}$ was due to 
the existence of comparatively strong bonding and higher $H$ value. Since high $H$ in DLC films is always accompanied by high $\sigma$, therefore estimation of hardness per unit stress $(H / \sigma)$ and plastic resistance parameter per unit stress $[(H / E) / \sigma]$ can provide complete information about nanomechanical properties due to combined effect. The variation of self bias versus $H / \sigma$ is depicted in Figure $7(\mathrm{~b})$. From the figure, it is evident that $H / \sigma$ was decreased with increase in self bias due to initiation of graphite-like $\mathrm{sp}^{2}$ bonding as well as increase in $R_{a}$ and particle size. The variation of self bias versus $(H / E) / \sigma$ is shown in Figure $7(\mathrm{c})$. Observed $(H / E) / \sigma$ values also followed similar trend and were found to decrease with increasing self bias due to same effect as discussed just above. It is to be noted that higher values of $H$ and $H / E$ and lower value of $\sigma$ give higher value of $H / \sigma$ and $(H / E) / \sigma$ and therefore, provide better quality films. Obtained excellent properties at $-125 \mathrm{~V}$ made it an appropriate self bias to design good quality $\mathrm{Cu} / \mathrm{DLC}$ bilayer films. In addition, the values of ER, $h_{\text {res }} / h_{\text {max }}$ and $U_{r}$ in pure DLC film deposited at $-125 \mathrm{~V}$, were also estimated and found to be $73 \%, 0.27$, and $3 \times 10^{-10} \mathrm{~J}$, respectively. From results of DLC and $\mathrm{Cu} / \mathrm{DLC}$ bilayer films, it was clearly seen that addition of $\mathrm{Cu}$ layer enhanced not only adhesion as well as structural properties but also improved nanomechanical properties.

\section{Conclusions}

In the present work, the role of sandwich $\mathrm{Cu}$ layer and effect of self bias on structural and nanomechanical properties of $\mathrm{Cu} / \mathrm{DLC}$ bilayer films have been discussed. The Cu/DLC bilayer films were grown using hybrid system involving RF-PECVD and RF-sputtering techniques under varied self bias from -125 to $-225 \mathrm{~V}$. The mean roughness and size of particles were found to increase with increasing self bias. The residual stress was reduced significantly due to addition of sandwich $\mathrm{Cu}$ layer. The DLC film deposited at $-125 \mathrm{~V}$ and having no $\mathrm{Cu}$ layer exhibited residual stress 1.8 GPa, which decreased to $0.95 \mathrm{GPa}$ for $\mathrm{Cu} / \mathrm{DLC}$ bilayer film deposited at same self bias $(-125 \mathrm{~V})$. Further, observed nominal increase in residual stress with increase of self bias in $\mathrm{Cu} / \mathrm{DLC}$ bilayer films accompanied by increase of energy of bombardment ions/atoms, which results in increase of mismatch at interface that confirmed by increase of mean roughness. With addition of sandwich $\mathrm{Cu}$ layer, nominal increase in $H$ and $E$ values was also observed. In addition, calculated various other mechanical parameters also exhibited excellent nanomechanical properties due to presence of sandwich $\mathrm{Cu}$ layer and correlated with each other as well as with self bias. In summary, sandwich $\mathrm{Cu}$ layer not only improves the adhesion but also improves the structural and nanomechanical properties and made $\mathrm{Cu} / \mathrm{DLC}$ bilayer films as an excellent hard and protective coating on cutting tools, automobile parts, magnetic storage media, razor blades, and solar cells.

\section{Acknowledgments}

The authors are grateful to the Director, National Physical Laboratory, New Delhi (India) for his kind support. Authors acknowledge Mr. Sandeep and Mr. Samantha for providing AFM measurement facility. One of the authors N. Dwivedi acknowledges Ministry of New and Renewable Energy Government of India for providing financial support through NRE fellowship. This research is sponsored by CSIR, Government of India, through the Network Project NWP-0027.

\section{References}

[1] S. Bec, A. Tonck, and J. Fontaine, "Nanoindentation and nanofriction on DLC films," Philosophical Magazine, vol. 86, no. 33-35, pp. 5465-5476, 2006.

[2] N. Dwivedi, S. Kumar, C. M. S. Rauthan, and O. S. Panwar, "Nanoindentation measurements on nitrogen incorporated diamond-like carbon coatings," Applied Physics A, vol. 102, pp. 225-230, 2011.

[3] C. A. Charitidis, "Nanomechanical and nanotribological properties of carbon-based thin films: a review," International Journal of Refractory Metals and Hard Materials, vol. 28, no. 1, pp. 51-70, 2010.

[4] H. S. Zhang and K. Komvopoulos, "Surface modification of magnetic recording media by filtered cathodic vacuum arc," Journal of Applied Physics, vol. 106, no. 9, Article ID 093504, 2009.

[5] N. Dwivedi, S. Kumar, D. Kaur, C. M. S. Rauthan, and O. S. Panwar, "Mechanical properties of nanostructured copper/hydrogenated amorphous carbon multilayer films grown in a low base vacuum system," Optoelectronics and Advanced Materials, vol. 4, no. 4, pp. 604-609, 2010.

[6] A. Grill, "Plasma-deposited diamondlike carbon and related materials," IBM Journal of Research and Development, vol. 43, no. 1-2, pp. 147-161, 1999.

[7] S. S. Tinchev, Y. Dyulgerska, P. Nikolova, D. Grambole, U. Kreissig, and T. Z. Babeva, "Optical properties of PECVD deposited DLC films prepared with air addition," Journal of Optoelectronics and Advanced Materials, vol. 8, no. 1, pp. 308311, 2006.

[8] S. Kumar, N. Dwivedi, C. M. S. Rauthan, and O. S. Panwar, "Properties of nitrogen diluted hydrogenated amorphous carbon (n-type a-C:H) films and their realization in ntype a-C:H/p-type crystalline silicon heterojunction diodes," Vacuum, vol. 84, no. 7, pp. 882-889, 2010.

[9] C. Godet, S. Kumar, and V. Chu, "Field-enhanced electrical transport mechanisms in amorphous carbon films," Philosophical Magazine, vol. 83, no. 29, pp. 3351-3365, 2003.

[10] N. Dwivedi, S. Kumar, C. M. S. Rauthan, and O. S. Panwar, "Role of metallic Ni-Cr dots on the adhesion, electrical, optical and mechanical properties of diamond-like carbon thin films," Plasma Processes and Polymers, vol. 8, no. 2, pp. 100-107, 2011.

[11] Z. B. Zhou, R. Q. Cui, Q. J. Pang, G. M. Hadi, Z. M. Ding, and W. Y. Li, "Schottky solar cells with amorphous carbon nitride thin films prepared by ion beam sputtering technique," Solar Energy Materials and Solar Cells, vol. 70, no. 4, pp. 487-493, 2002.

[12] M. S. Choi, J. H. Kim, and Y. S. Kim, "Field-emission characteristics of nitrogen-doped diamond-like carbon film deposited by filtered cathodic vacuum arc technique," Journal of Non-Crystalline Solids, vol. 324, no. 1-2, pp. 187-191, 2003.

[13] W. I. Milne, "Electronic devices from diamond-like carbon," Semiconductor Science and Technology, vol. 18, no. 3, pp. S81S85, 2003.

[14] N. Dwivedi, S. Kumar, C. M. S. Rauthan, O. S. Panwar, and P. K. Siwach, "Photoluminescence and electrical conductivity 
of silicon containing multilayer structures of diamond like carbon," Journal of Optoelectronics and Advanced Materials, vol. 11, no. 11, pp. 1618-1626, 2009.

[15] S. Kumar, P. N. Dixit, D. Sarangi, and R. Bhattacharyya, "Possible solution to the problem of high built-up stresses in diamond-like carbon films," Journal of Applied Physics, vol. 85, no. 7, pp. 3866-3876, 1999.

[16] F. L. Freire, "Amorphous hydrogenated carbon films: effects of nitrogen and fluorine incorporation on the film microstructure and mechanical properties: a review," Journal of NonCrystalline Solids, vol. 304, no. 1-3, pp. 251-258, 2002.

[17] P. Xu, J. J. Li, Q. Wang, Z. L. Wang, C. Z. Gu, and Z. Cui, "Improving mechanical properties of amorphous carbon nitride films by titanium doping," Journal of Applied Physics, vol. 101, no. 1, Article ID 014312, 2007.

[18] Y. Pauleau, F. Thiéry, P. B. Barna et al., "Nanostructured copper/hydrogenated amorphous carbon composite films prepared by microwave plasma-assisted deposition process from acetylene-argon gas mixtures," Reviews on Advanced Materials Science, vol. 6, no. 2, pp. 140-149, 2004.

[19] D. Batory, A. Stanishevsky, and W. Kaczorowski, "The effect of deposition parameters on the properties of gradient a$\mathrm{C}: \mathrm{H} / \mathrm{Ti}$ layers," Journal of Acheivements in Materials and Manufacturing Engineering, vol. 37, pp. 381-386, 2009.

[20] N. Dwivedi, S. Kumar, Ishpal et al., "Studies of nanostructured copper/hydrogenated amorphous carbon multilayer films," Journal of Alloys and Compounds, vol. 509, no. 4, pp. 12851293, 2011.

[21] X. Han, J. Zhu, J. Han, M. Tan, and W. Gao, "Stress, microstructure and mechanical properties of graded multilayer tetrahedral amorphous carbon films," Applied Physics A, vol. 91, no. 3, pp. 529-533, 2008.

[22] S. Kumar, P. N. Dixit, O. S. Panwar, and R. Bhattacharyya, "Correlation of residual stress with optical absorption edge in diamond-like carbon films," Diamond and Related Materials, vol. 12, no. 9, pp. 1576-1583, 2003.

[23] A. Y. Wang, H. S. Ahn, K. R. Lee, and J. P. Ahn, "Unusual stress behaviour in $\mathrm{W}$-incorporated hydrogenated amorphous carbon films," Applied Physics Letters, vol. 86, no. 1-3, Article ID 111902, 2005.

[24] B. Jönsson and S. Hogmark, "Hardness measurements of thin films," Thin Solid Films, vol. 114, no. 3, pp. 257-269, 1984.

[25] A. Erdemir and C. Donnet, "Tribology of diamond-like carbon films: recent progress and future prospects," Journal of Physics D, vol. 39, no. 18, article R01, pp. R311-R327, 2006.

[26] P. J. Fallon, V. S. Veerasamy, C. A. Davis et al., "Properties of filtered-ion-beam-deposited diamondlike carbon as a function of ion energy," Physical Review B, vol. 48, no. 7, pp. 47774782, 1993.

[27] S. Singh, M. Pandey, R. Kishore et al., "Influence of impinging ion energy on the bonding and mechanical characteristics of DLC films deposited by microwave ECR plasma CVD," Plasma Processes and Polymers, vol. 5, no. 9, pp. 853-860, 2008.

[28] N. Bahadur, A. K. Srivastava, S. Kumar, M. Deepa, and B. Nag, "Influence of cobalt doping on the crystalline structure, optical and mechanical properties of $\mathrm{ZnO}$ thin films," Thin Solid Films, vol. 518, no. 18, pp. 5257-5264, 2010. 

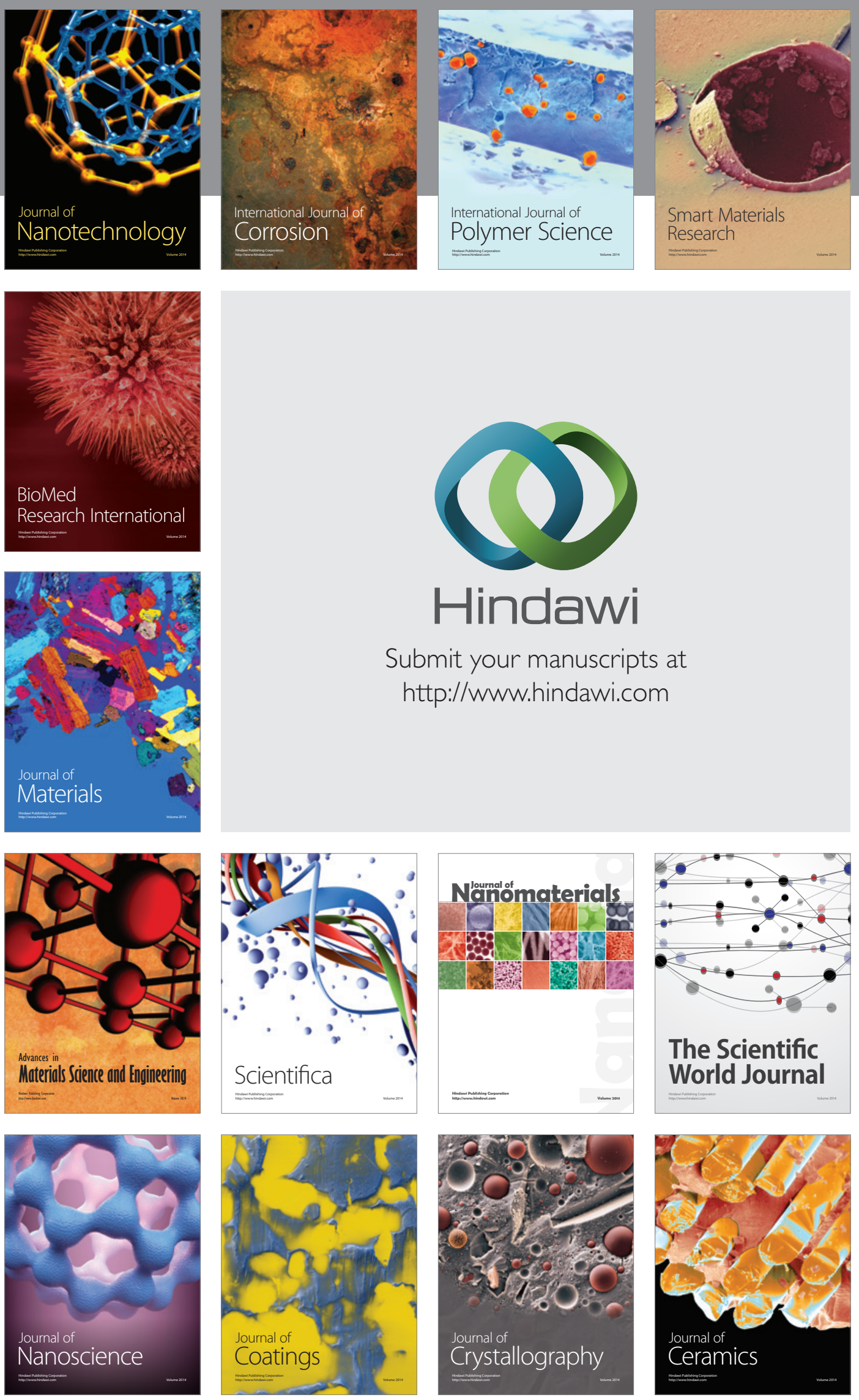

The Scientific World Journal

Submit your manuscripts at

http://www.hindawi.com

\section{World Journal}

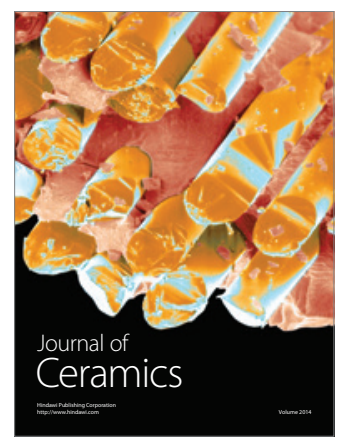

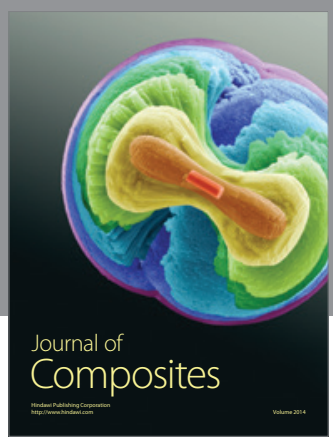
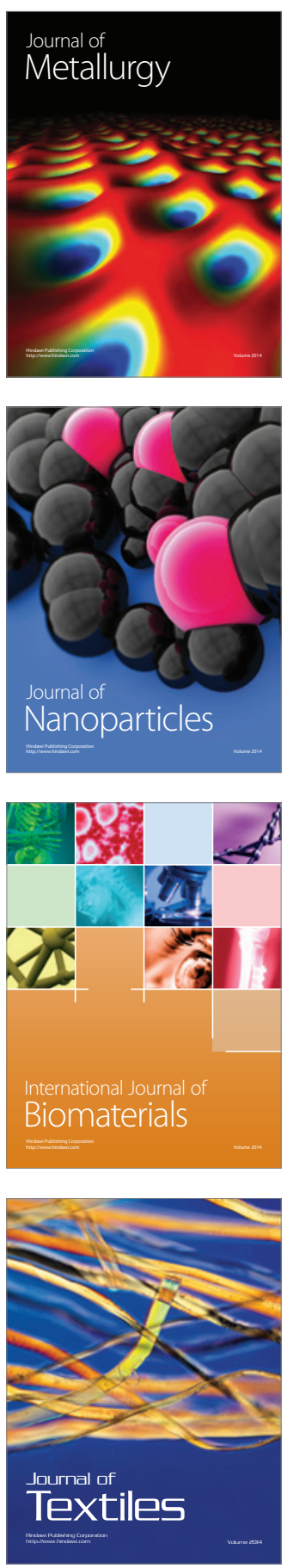